\title{
FLUID INCLUSION ANALYSIS OF FLUORITE IN POST-ALLEGHANIAN VEINS, VALLEY AND RIDGE PROVINCE, CENTRAL PENNSYLVANIA
}

Shanna Law (shannalaw716@gmail.com) and Laurence Mutti (mutti@juniata.edu), Department of Geology, Juniata College, Huntingdon, PA

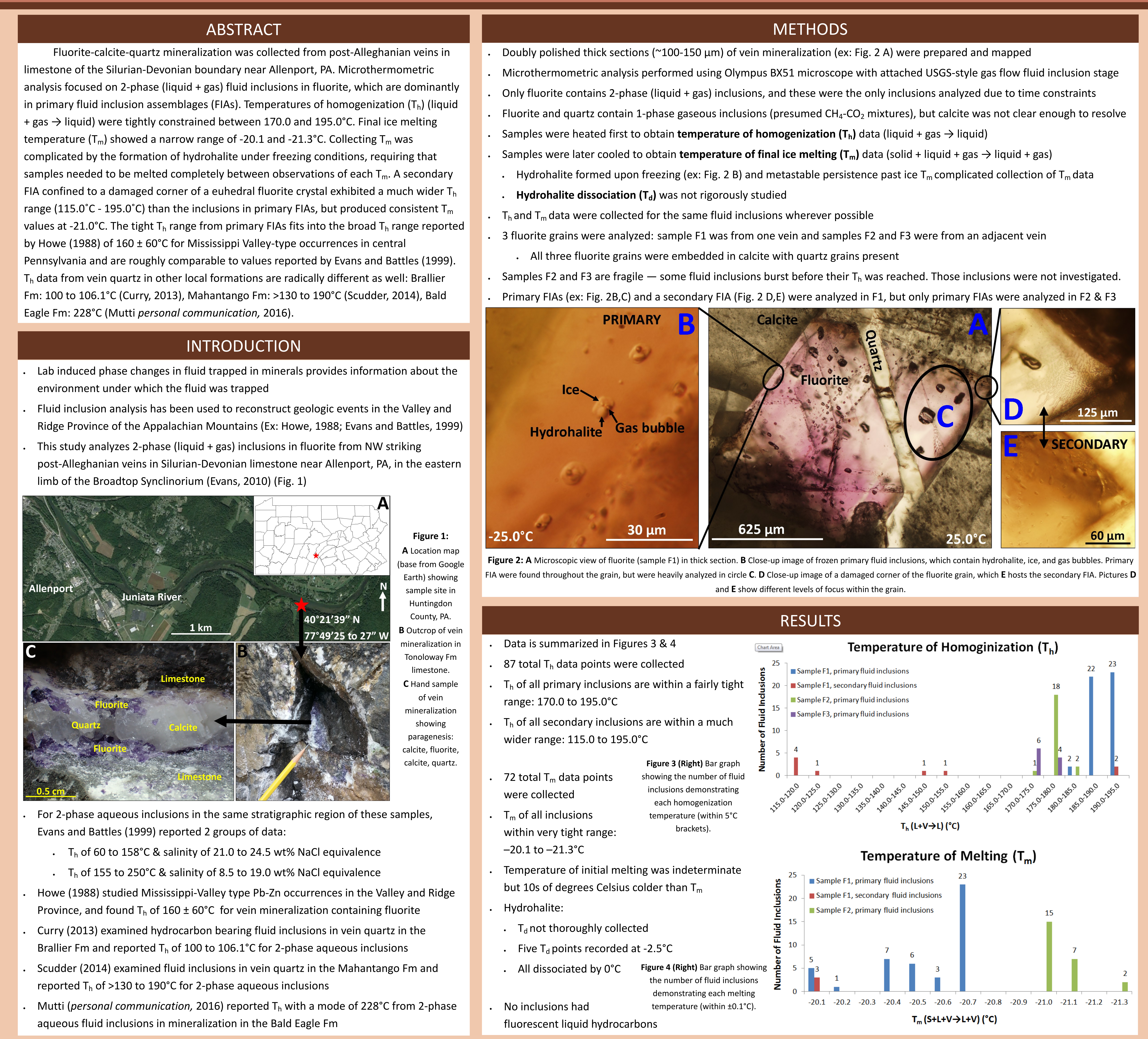

DISCUSSION

The salinity of the liquid in the inclusions can be determined in NaCl wt\% equivalence by comparing observed $\mathrm{T}_{\mathrm{m}}$ to the $\mathrm{NaCl}_{\mathrm{H}} \mathrm{H}_{2} \mathrm{O}$ vapor-saturated phase relations diagram (Bodnar, 2003) Within experimental error, $\mathrm{T}_{m}$ is indistinguishable from the eutectic temperature of the $\mathrm{NaCl}_{2} \mathrm{H}_{2} \mathrm{O}$ binary system $\left(-21.2^{\circ} \mathrm{C}\right)$, which corresponds to $23.2 \mathrm{NaCl}$ wt\% equiv.

Presence of hydrohalite on the liquidus demands salinities between 23.3 to $26.3 \mathrm{NaCl}$ wt\% equiv. indicating highly saturated brines (consistent with basinal brines)

Temperature of initial melting $<<-21.2^{\circ} \mathrm{C}$ requires the presence of divalent ions

$\mathrm{Ca}^{+2}$ is abundant considering the presence of fluorite and calcite

There is no mineralogical indication of sulfate or sulfide in the system $T_{h}$ of Primary FIAs

Consistent $T_{h}$ throughout $F 1$ indicate consistent temperature during fluorite growth - $T_{h}$ give a minimum entrapment temperature of 170.0 to $195.0^{\circ} \mathrm{C}$, which corresponds to a minimum depth of 8.5 to $9.75 \mathrm{~km}$, if one assumes a geothermal gradient of $20^{\circ} \mathrm{C} / \mathrm{km}$ $1 \mathrm{~kb} / 3 \mathrm{~km}$

- If we assume $P_{f}=P_{L}$ then $280 \mathrm{MPa}$ indicates a temperature Secondary FIA

Avg. $T_{m}$ of secondary fluid inclusions is $-20.1^{\circ} \mathrm{C}$, which fits in the range of the primary $\mathrm{F} \mid \mathrm{As}$, and indicates that the entrapped fluid must still be highly saline basinal brine

$T_{h}$ ranges $80^{\circ} \mathrm{C}\left(115.0-195.0^{\circ} \mathrm{C}\right)$, suggesting there were pulses of fluid through the system much later during prolonged uplift

\section{Relevance to Other Work}

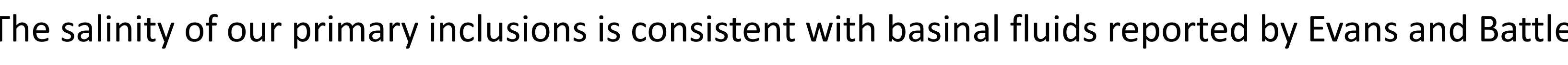
(1999)

- $T_{h}$ reported by Evans and Battles (1999) for salinities similar to our samples are lower than our $T_{h}$ suggesting that our fluid was trapped in a deeper and hotter environment or during an episode of elevated thermal pulse

- Our $T_{h}$ fits within the $T_{h}$ range given by Howe (1988), but the mineralization at Allenport distinctly lacks the sulfide mineralization of the Mississippi Valley-type occurrences studied by Howe The mineralization of our study is stratigraphically below Curry's (2013) and Scudder's (2014) samples. Our $T_{h}$ are within the range of Scudder's data but completely different to Curry's data and lack the hydrocarbon inclusions dominant in Curry's samples.

The $T_{h}$ values reported for the mineralization in the stratigraphically lower Bald Eagle formation are hotter than our $T_{h}$ values, as expected

Future Investigations

Investigation of 1-phase gaseous inclusions by freezing studies and Raman spectroscopy

More field work, especially structural data, to aid contextualization to the study to other data sets

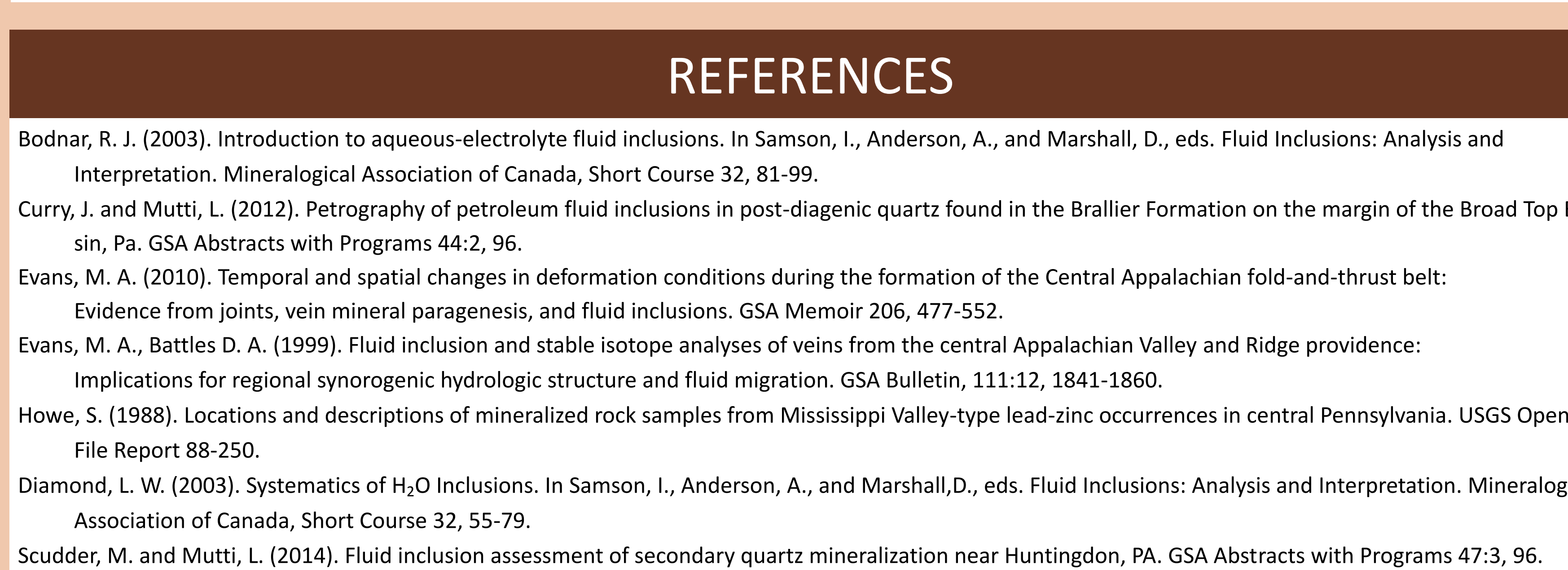

ACKNOWLEDGEMENTS

Credit goes to Nicholas Alin, Elias Michaelangel,o, and Cale McMullen for making the initial
the sample site, and thanks to Nicholas Allin for repeated transportation to the sample site 